\title{
Behavioural Signs and Fertility Response Following Spontaneous and Ovsynch Induced Estrus in Sahiwal Cows
}

\author{
Amninder Singh, Narinder Singh*, Mrigank Honparkhe, \\ Vijay Singh Malik and Prahlad Singh
}

Department of Veterinary Gynaecology and Obstetrics, GADVASU, Ludhiana, India

*Corresponding author

\begin{abstract}
A B S T R A C T
The study was designed to evaluate behavioural estrus signs and fertility response following spontaneous and Ovsynch induced estrus in Sahiwal cows. Group 1: (Spontaneous estrus group; $n=20$ ) cows were observed visually and ultrasonographically from a random day till occurrence of spontaneous estrus and ovulation. Group 2 (Ovsynch group; $\mathrm{n}=10$ ) were administered with standard Ovsynch protocol (two GnRH $20 \mu \mathrm{g}$ on day 0 and 9 and PGF $500 \mu \mathrm{g}$ on day 7, i.m.) started at random day of estrous cycle to synchronize estrus and ovulation. In group 1, the estrus characteristics viz. cervico-vaginal mucus discharge, mounting, vulvar swelling, bellowing and frequent urination were observed in 70, 65, 30, 10 and 20 percent cows, respectively as compared to 70, 40, 20, 30 and 20 per cent in group 2. In ovsynch group, higher size of dominant follicle (7 to 10 $\mathrm{mm})$ at time of prostaglandin injection favoured subsequent ovulation, whereas, cows having smaller dominant follicle $(<7 \mathrm{~mm}$ size) failed to undergo ovulation. Similarly, average diameter of DFs on Day 10 was higher in cows showing ovulatory estrus as compared to non ovulatory cows in the Ovsynch group (11.9 \pm 0.27 vs. 9.25 \pm 1.18 , respectively, $\mathrm{P}<0.05$ ). Results suggested that $\mathrm{CVM}$ discharge and mounting activity were the two prominent signs expressed during estrus and efficacy of Ovsynch protocol initiated at random day of estrous cycle was lower in inducing ovulatory estrus and pregnancy in comparison to spontaneous estrus in Sahiwal cows.
\end{abstract}

\section{Introduction}

The precise detection of estrus is essential to ensure high herd fertility and economic returns from a dairy farm. Generally, majority of farmers use visual observations to detect estrus in cattle. However, Bos indicus do not exhibit pronounced behavioural estrus signs making estrus detection a difficult task.
Sahiwal is considered as the best milch breed of indigenous cattle. Like other breeds of Bos indicus cattle, estrus detection is difficult in Sahiwal cows due to less prominent estrus signs and shorter duration of standing estrus (average 10 hours) as compared to Bos taurus cows (Galina and Arthur 1990, Pinheiro et al., 1998). Application of estrus detection aids have been found advantageous, however, their 
use require extra expenditure which may not be feasible and economical for poor and marginal farmers. Fixed timed artificial insemination (FTAI) protocols could be used to achieve acceptable pregnancy rates without estrus detection in cattle. However, protocols developed in Bos taurus sometime did not yield similar success in Bos indicus cows (Pinheiro et al., 1998) this could be due to minor differences observed in their endocrinology and physiology. Therefore, present study was planned to compare the behavioural estrous signs and fertility response following spontaneous and Ovsynch induced estrus in Sahiwal cows.

\section{Materials and Methods}

Thirty pluriparous Sahiwal cows weighing between 350 to $450 \mathrm{Kg}, 60$ to 90 days postpartum, having apparently normal genitalia and estrous cycle were included in the study. Cows were maintained under loose housing system and were fed with chaffed green fodder, wheat straw, concentrates, common salt, mineral mixture and ad libitum drinking water.

Cows were divided into following two groups-

Group 1: Spontaneous estrus group; Sahiwal cows $(n=20)$ were followed to detect spontaneous estrus through visual observations and ultrasonography. No treatment was administered in this group.

Group 2: Ovsynch group; Sahiwal cows $(n=10)$ were administered standard Ovsynch protocol at the at random stage of estrous cycle to synchronize estrus. On day $0, \mathrm{GnRH}$ analogue (20 $\mu \mathrm{g}$ Buserelin acetate) was administered followed by PGF2 $\alpha$ (Cloprostenol $500 \mu \mathrm{g}$ ) on day 7 and again GnRH analogue (20 $\mu \mathrm{g}$ Buserelin acetate) on day 9.
All cows were observed visually to record estrual signs like cervico-vaginal mucous (CVM) discharge, mounting activity, bellowing, micturition etc. The ovaries of enrolled animals were scanned daily in Spontaneous estrus group till ovulation and on days $0,3,7,9,10,11,12$ in the Ovsynch group to monitor number, size, fate of the follicles and size of corpus luteum.

\section{Statistical analysis}

The data was analyzed for means and standard errors (SE) for all variables. After confirming the normality of data and homogeneity of variance, Student's t test (two tailed) was applied to compare average size of follicles in different treatment groups.The ovulation and pregnancy rates were compared using chi-square test. A probability level of $\mathrm{P}<0.05$ was considered significant.

\section{Results and Discussion}

The characteristics of estrus and fertility response in spontaneous and Ovsynch induced estrus are depicted Table 1. In the spontaneous estrus group, 75 percent of the cows $(n=20)$ showed either one or combination of behavioural estrus signs and 25 percent did not show any visual signs of estrus but were found in estrus on per rectal and ultrasonographic examination .Two most prominent behavioural signs of estrus observed were the CVM discharge and mounting activity, which were expressed by 70 and 65 percent of cows, respectively. Similar to the present study, Mattoni et al., (1988) observed vaginal mucus discharge in $64 \%$ of estrus periods in Zebu cattle. Unalan et al., (2016) stated that the standing to be mounted was the most observable behaviour estrus sign, followed by mounting, vaginal mucus discharging, and the other estrus signs in Holstein heifers. 
Chicoteau et al., (1989) also observed that acceptance of mounting as the characteristic sign of estrus in Baoule cows. Similar to this, Roelofs et al., (2005a) observed mounting activity among herdmates in $90 \%$ cases of estrus in HF cows which was higher than recorded in the present study. Roelofs et al., (2005b) further reported that the percentage of cows expressing mounting activity was higher when more than two cows were in estrus simultaneously. Membrive (2000) recorded the number of mounts during estrus and reported $23.0 \pm 16.9$ mounts per estrus, that were distributed in $10.0 \pm 9.7$ mounts (43.5\%) between $7 \mathrm{AM}$ to $7 \mathrm{PM}$. and $13.0 \pm 12.4$ mounts $(56.5 \%)$ between 7 PM to 7 AM in Bos indicus $\times$ Bos taurus heifers.

The percentage of cows expressing bellowing sign was low in the present study. Contrary to the present study, Singh et al., (1984) observed that segregation and bellowing confirmed estrus in $83.69 \%$ and $80.43 \%$ cattle, respectively. Srivastava et al., (1977) stated that to detect a cow in proper heat, for successful conception the visual signs of being mounted, chasing and teaser mounting were the reliable indicators. However, Llewelyn et al., (1987) observed that only $27 \%$ cows showed mounting behaviour in Boran cattle.

Following the spontaneous estrus, the percentages of other behavioural estrus signs viz. vulvar swelling, bellowing and frequent urination were comparatively lower than that of the CVM discharge and mounting activity. This could be partially due to the fact that cows were observed visually for half an hour in the morning $7 \mathrm{PM}$ and evening $6 \mathrm{PM}$ for expression of estrus signs in the present study. Roelofs et al., (2005b) reported that intensive visual observations of 30 minutes rounds at 3 hours intervals were required to achieve $\sim 80$ percent precision in estrus detection rate in cattle. Cows were kept in loose housing system which could be another reason for differential expression of estus signs in the present study compared to others. Roelofs et al., (2010) also reported that expression of estrus could be influenced by postpartum days, lactation number, milk production, health, nutrition, season, housing and herd size.

Out of the 10 cows administered Ovsynch protocol, behavioural estrus signs viz. CVM discharge, mounting activity, vulvar swelling, bellowing and micturition were present in 7 cows, whereas, 3 cows did not show any estrus sign. This could be due to the fact that possibly three cows with no visible estrus signs didn't respond to the Ovsynch protocol and were not in estrus which was also indicated by per rectal and ultrasonographic findings. Otherwise, no significance difference in expression of estrus signs was observed between Ovsynch induced estrus and spontaneous estrus in the present study. Udin et al., (2017) evaluated the efficacy of Ovsynch protocol in Simmental cattle and observed that 40 percent of the cows showing behavioural estrus signs had CVM discharge and $100 \%$ cows were having intense uterine tone. Ammu et al., (2012) observed that 83.33\% Gir cows showed more prominent behavioural estrus signs especially uterine tone and mucus discharge following ovsynch.

Uterine tonicity during estrus is one of the important criteria for evaluation of estrus. In the spontaneous estrus group, 70 percent of the cows had intense uterine tone and remaining 30 percent had moderate uterine tone. None of the cow showing behavioural estrus signs had no or low uterine tone in the spontaneous estrus group (Table 1). In a similar study, Gunasekaran et al., (2008) reported higher incidence of moderate uterine tone compared to mild and intense uterine tone (69.8 vs. 24.3 and 5.8 percent) in crossbred cows. However, Singh and Kharche 
(1985) reported that 63.9 percent cows showed intense uterine tone followed by low tone in 26.39 and atonic in $9.72 \%$ Crossbred cows.

Results of present study showed that the percentage of cows with Intense, Moderate and Low uterine tone following Ovsynch induced estrus was 40, 30 and 30 percent, respectively (Table 1). Whereas, in case of spontaneous estrus, none of the cow had no or low uterine tone indicating that the three cows of Ovsynch group with low or no uterine tone might have not responded to the treatment.

\section{Ovulation and pregnancy rate}

In the spontaneous estrus group, 18 cows expressed ovulation and 2 cows failed to ovulate resulting in 90 percent ovulation rate. In the Ovsynch, 6 cows ovulated and 4 failed to ovulate as confirmed by ultrasonographic examination. Lower ovulation rate observed could be due to failure of three cows to respond to Ovsynch protocol. Hassan et al., (2017) reported 50 percent ovulation rate following Ovsynch protocol which was comparable to the ovulation rate achieved in the present study. Sartori et al., (2001) and Gimenes et al., (2008) stated that full ovulatory capacity was obtained when the DF reaches a diameter of $10 \mathrm{~mm}$ in Bos indicus and $12 \mathrm{~mm}$ in Bos taurus cattle. However, Tortorella et al., (2013) obtained a low ovulation rate even in large follicles following eCG treatment.

Out of 20 inseminated cows, 11 got pregnant resulting in 55 percent pregnancy rate in the Spontaneous estrus group. In the Ovsynch group, out of the six cows ovulated, 3 become pregnant following AI resulting in overall pregnancy rate of 30 percent in the Ovsynch group. In similar studies, Ammu et al., (2012) and Udin et al., (2017) obtained 50 and 60 conception rate by Ovsynch in Gir and Simmental cows, respectively which was higher than achieved in the present study. The pregnancy rates depending upon type of estrus sign expressed following the Ovsynch induced and the spontaneous estrus was also analysed. No significance difference in pregnancy rate based on the type of estrus sign expressed between the Ovsynch and the spontaneous estrus group was observed (Table 2). However, in the Ovsynch group none of the cows having low or moderate uterine tone conceived indicating that cows were not in proper estrus at the time of insemination.

In both the groups, cows expressing behavioural signs had higher pregnancy rate compared to cows with no visible signs of estrus (66.7 vs. 20 and 42.8 vs 0 , respectively). Similarly, higher percentage of cows got pregnant in both the groups under study when they had intense uterine tone indicating that intense uterine tone was a reliable indicator of estrus expression. Gunasekaran et al., (2008) found very high association between type of estrus sign exhibited and conception rate in the crossbred cows. Fernandes et al., (2001) suggested that use of Ovsynch protocol was more effective in synchronizing ovulation in cycling than non cycling Nellore cows, and reported higher pregnancy rate after FTAI (45\%) in cycling than in non-cycling cows (20\%). Lamb et al., (2001) and Larson et al., (2006) reported 56\% pregnancy rates in Bos taurus, while less than $33.5 \%$ was obtained in Bos indicus in $\mathrm{GnRH}$ based protocols by Saldarriaga et al., (2007) and Vasconcelos et al., (2009).

Effect of ovarian status, follicle size and growth rate on efficacy of Ovsynch protocol

\section{Ovarian status on Day 0}

The influence of ovarian status of Sahiwal cows administered Ovsynch protocol at random stage of estrous cycle was also 
evaluated in present study. Out of the total 6 ovulations recorded in the Ovsynch group, four occurred in cows having $\geq 8 \mathrm{~mm}$ Follicle $+\mathrm{CL}$ at the beginning of protocol. The average size of dominant follicle in these four cows was 9.2 \pm 0.80 . The results indicated that presence of DF measuring $\geq 8 \mathrm{~mm}+\mathrm{CL}$ favoured ovulation following administration of Ovsynch protocol.

Mapletoft et al., (2006) reviewed that the first $\mathrm{GnRH}$ administration of the Ovsynch protocol induced ovulation in the dominant follicle measuring $>10 \mathrm{~mm}$ in diameter which lead to emergence of new follicular wave at $48 \mathrm{hrs}$ of GnRH administration. Thus, the efficacy of GnRH protocol was expected to be better in cows having a follicle measuring $>10 \mathrm{~mm}$ diameter at the time of first $\mathrm{GnRH}$ administration. Similar trend was observed in the Sahiwal cows having $\geq 8 \mathrm{~mm}$ Follicle $+\mathrm{CL}$ at the time of first $\mathrm{GnRH}$ injection which showed higher ovulation rate than the rest of the animals (4/5 vs. $2 / 5)$. However, the results needed to be verified on larger population to generate statistically significant data.

\section{Size and growth rate of dominant follicles}

Effect of largest follicle present on day 7 and its growth rate in inducing ovulatory estrus was also analysed (Table 3). It was observed that the average size of the DF on day 7 was higher in ovulatory cows compared to anovulatory cows. In the Ovsynch group, the size of the DF on day 7 in the cows undergoing ovulation ranged from 7 to $10 \mathrm{~mm}$ and none of the cow having follicle measuring $<7 \mathrm{~mm}$ ovulated or expressed estrus behaviour. On Day 10, significantly higher average diameter of DF was observed in cows showing ovulatory estrus compared to anovulatory in the Ovsynch induced estrus $(11.9 \pm 0.27$ vs. $9.25 \pm 1.18$, respectively, $\mathrm{P}<0.05)$.

Table.1 The characteristics of estrus and fertility response following Spontaneous vs. Ovsynch induced estrus in Sahiwal cows

\begin{tabular}{|c|c|c|c|c|}
\hline S. No. & Parameters & $\begin{array}{c}\text { Spontaneous } \\
\text { Group }(n=20) \\
\%(n)\end{array}$ & $\begin{array}{c}\text { Ovsynch Group } \\
(\mathbf{n}=\mathbf{1 0}) \\
\%(\mathbf{n})\end{array}$ & P Value \\
\hline \multirow[t]{6}{*}{1} & Behavioural estrus signs & $75(15)$ & $70(7)$ & 0.770 \\
\hline & i. CVM discharge & $70(14)$ & $40(4)$ & 0.113 \\
\hline & ii. Vulvar swelling & $30(6)$ & $20(2)$ & 0.559 \\
\hline & iii. Mounting & $65(13)$ & $30(3)$ & 0.070 \\
\hline & iv. Bellowing & $10(2)$ & $20(2)$ & 0.447 \\
\hline & v. Frequent urination & $20(4)$ & $20(2)$ & 1 \\
\hline 2 & No visible estrus signs & $25(5)$ & $30(3)$ & 0.770 \\
\hline \multirow[t]{4}{*}{3} & Uterine tonicity & & & \\
\hline & i. No or Low uterine tone & 0 & $30(3)$ & 0 \\
\hline & ii. Moderate uterine tone & $30(6)$ & $30(3)$ & 1 \\
\hline & iii. Intense uterine tone & $70(14)$ & $40(4)$ & 0.113 \\
\hline 4 & Ovulation rate & $90(18)$ & $60(6)$ & 0.052 \\
\hline 5 & Pregnancy rate & $55(11)$ & $30(3)$ & 0.195 \\
\hline
\end{tabular}


Table.2 Pregnancy rate in relation to expression of estrus signs following Spontaneous vs. Ovsynch induced estrus in Sahiwal cows

\begin{tabular}{|c|c|c|c|}
\hline \multirow{2}{*}{ SN } & \multirow{2}{*}{ Parameters } & \multicolumn{2}{|c|}{ Pregnancy rate (n) } \\
\cline { 3 - 4 } & & Spontaneous Group & Ovsynch Group \\
\hline \multirow{2}{*}{$\mathbf{1}$} & Behavioural estrus sign & $66.7(10 / 15)$ & $42.8(3 / 7)$ \\
\cline { 2 - 4 } & i. $\quad$ CVM discharge & $57(8 / 14)$ & $50(2 / 4)$ \\
\cline { 2 - 4 } & ii. $\quad$ Vulvar swelling & $50(3 / 6)$ & $50(1 / 2)$ \\
\hline \multirow{2}{*}{} & iii. $\quad$ Mounting & $54(7 / 13)$ & $66.7(2 / 3)$ \\
\hline \multirow{2}{*}{} & iv. $\quad$ Bellowing & $100(2 / 2)$ & $100(2 / 2)$ \\
\hline $\mathbf{2}$ & v. $\quad$ Frequent urination & $75(3 / 4)$ & $0(0 / 3)$ \\
\hline $\mathbf{3}$ & Uterine tonicity & $20(1 / 5)$ & $0(0 / 3)$ \\
\hline \multirow{2}{*}{} & i. $\quad$ No or Low uterine tone & 0 & $75(3 / 4)$ \\
\hline & ii. $\quad$ Moderate uterine tone & $37.5(3 / 8)$ & $50(3 / 6)$ \\
\hline \multirow{2}{*}{$\mathbf{4}$} & iii. $\quad$ Intense uterine tone & $75(9 / 12)$ & $01.1(11 / 18)$ \\
\hline
\end{tabular}

Table.3 Dominant follicle size and its growth rate (Ovulatory vs. Anovulatory estrus) following Ovsynch protocol

\begin{tabular}{|c|c|c|c|c|}
\hline SN & Parameter & $\begin{array}{l}\text { Ovulatory } \\
\text { Estrus }\end{array}$ & $\begin{array}{l}\text { Anovulatory } \\
\text { Estrus }\end{array}$ & Overall \\
\hline 1 & No. of cows & 6 & 4 & 10 \\
\hline 2 & $\begin{array}{l}\text { Av. Dominant Follicle } \\
\text { Size Day } 7(\mathrm{~mm})\end{array}$ & $8.3 \pm 0.55(7-10)$ & $\begin{array}{c}6.5 \pm 1.55(4- \\
11)\end{array}$ & $7.6 \pm 0.71(4-11)$ \\
\hline 3 & $\begin{array}{l}\text { Av. Dominant Follicle } \\
\text { Size on Day } 10(\mathrm{~mm})\end{array}$ & $\begin{array}{c}11.9 \pm 0.27^{\mathrm{a}} \\
(11-13)\end{array}$ & $\begin{array}{l}9.25 \pm 1.18^{b} \\
(6-11)\end{array}$ & $\begin{array}{l}10.85 \pm 0.63 \\
(6 \text { to } 13)\end{array}$ \\
\hline 4 & $\begin{array}{l}\text { Follicle Growth Rate } \\
\text { from day } 7 \text { to } 10(\mathrm{~mm})\end{array}$ & $1.19 \pm 0.15$ & $0.91 \pm 0.41$ & $1.08 \pm 0.18$ \\
\hline
\end{tabular}

Values marked with different superscript within the same row differed significantly $\mathrm{P}<0.05$

The results of the study indicated that the growth rate of dominant follicle from day 7 to 10 was higher in cows having ovulatory estrus in comparison to the anovulatory estrus $(1.19 \pm 0.15 \mathrm{vs} . \quad 0.91 \pm 0.41 \mathrm{~mm}$ per day, respectively). This indicated that the actively growing follicles had more competence to undergo ovulation. Similar to our results, Udin et al., (2017) also observed that diameter of ovulatory follicle was more in ovsynch protocol than co-synch protocol $((10.53 \pm 2.66$ and $9.18 \pm 1.65, \mathrm{p}>0.05)$ in Simmental cows. Quezada et al., (2015) observed that the growth rate of preovulatory DF from deviation to ovulation was higher after synchronized estrus than after spontaneous estrus $(0.9 \pm 0.2$ and $0.8 \pm 0.2$ $\mathrm{mm} / \mathrm{d}$, respectively; $\mathrm{p}<0.05)$. Hassan et al., (2017) recorded $1.18 \pm 0.26 \mathrm{~mm}$ per day follicle growth rate from day 7 to day 10 , 
$12.30 \pm 0.92 \mathrm{~mm}$ average size of dominant follicle at the time of ovulation, and $27 \pm 5.56$ hours interval from the second $\mathrm{GnRH}$ to ovulation, $50 \%$ ovulation and $43 \%$ pregnancy rate following Ovsynch protocol in Sahiwal cows.

\section{Interval from PG to estrual discharge and ovulation}

In seven cows showing behavioural estrus signs, average interval from $P G$ to estrus discharge was $68.7 \pm 1.11 \mathrm{hrs}$ (range 66 to 72 hrs), whereas, the interval from $P G$ to ovulation was $86.0 \pm 2.00 \mathrm{hrs}$ (range 84 to 96 hours). Mattoni et al., (2000) observed that mean estrus interval from PGF2 $\alpha$ analogue treatment to the onset of estrus was shorter in the Zebu cows compared to Baoule cattle. Zebu showed estrus ranging from $48 \mathrm{hrs}$ to 60 hrs after treatment. The highest proportions of animals were observed in estrus over a period of $60 \mathrm{hrs}$ and $72 \mathrm{hrs}$ after treatment in Baoule cows. Pinheiro et al., (1998) reported that ovulation occurred $26.6 \mathrm{~h}$ after the onset of estrus in Nelore (Bos indicus) cows.

Kastelic and Ginther (1991) reported that the time from the administration of $\mathrm{PGF}_{2} \alpha$ to ovulation was 3 days, if there was an emergent DF and reached static phase; in that case the time from $\mathrm{PGF}_{2} \alpha$ to ovulation was 3 days. However, the time from $\mathrm{PGF}_{2} \alpha$ to ovulation was 4.5 days if a new DF emerged at the time of luteolysis.

In conclusions, cervicovaginal discharge and mounting activity were the two major behavioural signs of estrus in Sahiwal cows. In addition, the efficacy of Ovsynch protocol at random stage of estrous cycle in inducing ovulatory estrus and pregnancy was lower as compared to spontaneous estrus in Sahiwal cows. Further, large scale studies are required in Sahiwal cows to draw concrete results on efficacy of Ovsynch in this breed.

\section{Acknowledgements}

The authors thank Guru Angad Dev Veterinary and Animal Sciences University, Ludhiana, Punjab, India for the financial assistance under the RKVY project.

\section{Compliance with ethical standards}

The presented research was conducted in accordance with the ethical standards of Guru Angad Dev Veterinary and Animal Sciences University, Ludhiana, Punjab, India.

\section{References}

Ammu, Ramakrishnan, Dhami, A. J., Naikoo, M., Parmarand, B. C., Divekar, B. S. 2012. Estrus induction and fertility response in postpartum anestrus Gir cows. Indian Journal of Animal Reproduction 33: 37-42.

Chicoteau, P., Mamboue, E., Cloe, A., Bassinga, A. 1989. Oestrous behaviour of Baoule cows (Bos Taurus) in Burkina Faso. Animal Reproduction Science 21: 153-59.

Fernandes, P., Teixeria, A. B., Crocci, A. J. and Barros, C. M. 2001. Timed artificial insemination in beef cattle using GnRH agonist, PGF2 $\alpha$ and estradiol benzoate (EB). Theriogenology 55: 1521-32

Galina, C. S. and Arthur, G. H. 1990. Review on cattle reproduction in the trophics. Part 4. Oestrus cycle. Animal Breeding 50: 697-07.

Gimenes, L. U., Sa Filho, M. F., de Carvalho, N. A. T. de, Torres-Júnior, J. R., de Souza, A. H., Madureira, E. H. and Carvalho, J. B. P. de. 2008. Follicle deviation and ovulatory capacity in Bos indicus heifers. Theriogenology 69: 852-58.

Gunasekaran, M., Singh, C. and Gupta, A. K. 2008. Effect of estrus behaviour on 
fertility in crossbred cattle. Indian Veterinary Journal 85: 159-63.

Hassan, M., Husnain, A., Naveed, M. I., Riaz, U. and Ahmad, N. 2017. Effect of ovsynch versus prostaglandin $\mathrm{F} 2 \alpha$ protocol on estrus response, ovulation rate, timing of ovulation and pregnancy per artificial insemination in Sahiwal cows. Animal Science Journal 88: 445-450.

Kastelic and Ginther. O. J. 1991. Factors affecting the origin of the ovulatory follicle in heifers with induced luteolysis. Animal Reproduction Science 26: 13-24

Lamb, G., Stevenson, J., Kesler, D., Garverick, H., Brown, D. and Salfen, B. 2001. Inclusion of an intravaginal progesterone insert plus GnRH and prostaglandin F2alpha for ovulation control in postpartum suckled beef cows. Journal of Animal Science 79: 2253-59.

Larson, J., Lamb, G., Stevenson, J., Johnson, S., Day, M., Geary, T., and Di Costanzo, A. 2006. Synchronization of estrus in suckled beef cows for detected estrus and artificial insemination and timed artificial insemination using gonadotropinreleasing hormone, prostaglandin $\mathrm{F}$, and progesterone. Journal of Animal Science 84: 332-42.

Llewelyn, C A., Munro, C. D., Luckings, A. G., Jordt, T., Murray, M., and Lorenzini, E.1987. Behavioral and ovarian changes during the oestrous cycle in the Boran (Bos indicus). The British Veterinary Journal 143: 75-82.

Mapletoft, R. J. 2006. Bovine embryo transfer. IVIS. International Veterinary Information Service, Ithaca N Y. 2006.

Mattoni, M., and Ouedraogo, A. 2000. A comparative study on the estrous response to PGF2 $\alpha$ analogue treatment, and conception rates according to time of artificial insemination, in Zebu (Bos indicus) and Baoule (Bos taurus) cattle. Tropical Animal Health and Production 32: 127-34.

Mattoni, M., Mukasa-Mugerwa, G., Cecchini, G. and Sovani, S. 1988. The reproductive performance of East African (Bos indicus) Zebu cattle in Ethiopia. 1. Estrous cycle length, duration behaviour and ovulation time. Theriogenology 30: 961-971

Membrive, C. M. B. 2000. Estudo da sincronizacao das ondas foliculares e das caracteristicas de estros, por radio telemetria, em novilhas cruzadas (Bos indicus $\times$ Bos taurus) tratadas com acetate de melengestrol eprostaglandina associados a $\mathrm{Hcg}$, GnRH ou 17b estradiol + progesterone. Tesis de Maestria. Faculdade de Medicina Veterinaria e Zootecnia, Universidade de Sao Paulo, Sao Paulo.

Pinheiro, O., Barros, C., Figueiredo, R., Do Valle, E., Encarnacao, R., Padovani, C. 1998. Estrous behavior and the estrus to ovulation interval in nelore cattle (Bos indicus with natural estrus or estrus induced with prostaglandin F2 $\alpha$ or norgestomet and estradiol valerate. Theriogenology 49: 667-81.

Quezada-Casasola, A., Avendano-Reyes, L., Macias- Cruz, U. J.A., RamirezGodinez, A. J. and Rivas- Caceres, R. R. 2015. Estrous behavior, ovulatory follicle dynamics, and corpus luteum size in Creole cows after spontaneous or prostaglandin $\mathrm{F} 2 \alpha$-induced estrous. Revista Colombiana de Ciencias Pecuarias. 28(4): 303-312.

Roelofs, J. B., Van Eerdenburg, F. J. C. M., Soede, N. M., Kemp, B. 2005a. Pedometer readings for estrous detection and as predictor for time of 
ovulation in dairy cattle. Theriogenology 64: 1690-703.

Roelofs, J. B., Van Eerdenburg, F. J. C. M., Soede, N. M. and Kemp, B. 2005 b. Various behavioural signs of estrus and their relationship with time of ovulation in dairy cattle. Theriogenology 63: 1366-77.

Roelofs, J., López-Gatius, F., Hunter, R. H. F., van Eerdenburg, F. J. C. M., and Hanzen, C. 2010. When is a cow in estrus? Clinical and practical aspects. Theriogenology 74: 327-44.

Saldarriaga, J., Cooper, D., Cartmill, J., Zuluaga, J., Stanko, R. and Williams, G.. 2007. Ovarian, hormonal and reproductive events associated with synchronization of ovulation and timed appointment breeding ofinfluenced cattle using intravaginal progesterone, gonadotropin-releasing hormone, and prostaglandin $\mathrm{F}$. Journal of Animal Science 85: 151-62.

Sartori, R., Fricke, P. M., Ferreira, J. C., Ginther, O. and Wiltbank, M. C. 2001. Follicular deviation and acquisition of ovulatory capacity in bovine follicles. Biology of Reproduction 65: 1403-09.

Singh, G., Singh, G. B., Sharma, S. S. and Sharma, R. D. 1984. Studies on oestrus symptoms of buffalo heifers. Theriogenology 21: 849-58.

Singh, M. M. and Kharche, K. G. 1985. Sexual behaviour and reproductive efficiency of crossbred cows. Livestock Advisor. 85: 9-13.

Srivastava, P. K. 1977. A study on Herbal preparations on the postpartum anestrus animals. Indian Veterinary Journal 21: 231.

Tortorella, R. D., Ferreira, R., dos Santos, J. T., de Andrade Neto, O. S., Barreta, M. H., Oliveira, J. F., and Neves, J. P. 2013. The effect of equine chorionic gonadotropin on follicular size, luteal volume, circulating progesterone concentrations and pregnancy rates in anestrous beef cows treated with a novel fixed-time artificial insemination protocol. Theriogenology 79: 1204-1209.

Udin, Z., Rahim, F., Hendri, H. and Yellita, Y. 2017. Waktu dan Kemerahan Vulva Saat Inseminasi Buatan Merupakan Faktor Penentu Angka Kebuntingan Sapi di Sumatera Barat (Time and reddish sign of vulva during artificial insemination as a determinant factors on conception rate of cow in West Sumatera). Jurnal Veteriner 17: 501-09.

Unalan, A. 2016. Seasonal effects on behavioral estrus signs and estrus detection efficiency in Holstein heifers. Indian Journal Animal Research 50:185-89.

Vasconcelos, J. L. M., Sa Filho, O. G., Perez, G. C. and Silva, A. T. N. 2009 Intravaginal progesterone device and/or temporary weaning on reproductive performance of anestrous crossbred Angus $\times$ Nelore cows. Animal Reproduction Science. 111: 302-11.

\section{How to cite this article:}

Amninder Singh, Narinder Singh, Mrigank Honparkhe, Vijay Singh Malik and Prahlad Singh. 2020. Behavioural signs and fertility response following spontaneous and Ovsynch induced estrus in Sahiwal cows. Int.J.Curr.Microbiol.App.Sci. 9(05): 2229-2237. doi: https://doi.org/10.20546/ijcmas.2020.905.254 